\title{
Mídia-educação no currículo do ensino fundamental e interfaces com as tecnologias e os multiletramentos
}

\section{Media education in elementary school curriculum and interfaces with technologies and the multiliteracies}

\author{
Alexandre Passos Bitencourt ${ }^{*}$ \\ alexandreletras@hotmail.com \\ Universidade Federal de São Paulo (UNIFESP) \\ Orlando Vian Jr.** \\ orlando.unifesp@gmail.com \\ Universidade Federal de São Paulo (UNIFESP)
}

\begin{abstract}
RESUMO: O objetivo principal deste artigo é discutir a relevância da mídia-educação na interface com as Tecnologias Digitais da Informação e Comunicação e a Pedagogia dos Multiletramentos, a partir de uma experiência com a implantação da área de mídiaeducação no currículo de uma escola pública na cidade de São Paulo. Adotamos, para tal, princípios da mídia-educação e dos multiletramentos para analisar a produção de vídeos pelos alunos. Para tanto, discutiremos duas atividades produzidas por alunas do nono ano do Ensino Fundamental com o uso das tecnologias móveis e sua incorporação ao currículo escolar. Os resultados apontam que apenas considerar a presença da tecnologia na sala de aula não é suficiente, é necessária a adoção de abordagens relacionadas aos multiletramentos.
\end{abstract}

PALAVRAS-CHAVE: Mídia-educação; Currículo; Multiletramentos.

ABSTRACT: The main objective of this article is to discuss the relevance of media education in its interface with Information and Communication Digital Technologies and the Pedagogy of Multiliteracies, based on an experience with the implementation of the area of media education in the curriculum of a public school in the city of São Paulo. We adopted, for this purpose, media-education principles and multiliteracies to analyze videos produced by the students. In order to achieve this goal, we discuss two video production activities carried out by students in the ninth grade of elementary school with the use of mobile technologies in the school curriculum. The results show

\footnotetext{
* Mestre em Letras/ UNIFESP. Licenciado em Letras/ UNICASTELO. Professor efetivo da rede municipal de educação da cidade de São Paulo.

** Mestre e doutor em Linguística Aplicada e Estudos da Linguagem pela PUC-SP. Professor associado da Universidade Federal de São Paulo.
} 
that just considering the presence of technology in the classroom is not enough, it is necessary to adopt approaches related to multiliteracies.

KEYWORDS: Media education; Curriculum; Multiliteracies.

\section{Introdução: inserção da mídia-educação no ensino fundamental}

É comum o truísmo de que os jovens, no mundo de hoje, vivem conectados, e as mídias são parte integrante de suas vidas. Apenas a título de ilustração dessa realidade, pesquisa publicada pela Fundação Telefônica, em 2016, constatou que " $85 \%$ dos entrevistados usam o celular como principal dispositivo de acesso à internet. Esse índice representa um crescimento de $102 \%$ em relação à primeira edição do estudo, realizada em 2013" (JUVENTUDE CONECTADA 2, 2017, p. 21). Em uma nova edição, em 2018, foi lançada a Edição Especial Empreendedorismo, que pretendeu levantar "as percepções e experiências de brasileiros entre 15 e 29 anos no universo do empreendedorismo" no contexto dos rápidos avanços das tecnologias digitais.

Daí advém a importância de considerarmos a mídia-educação como forma de estabelecer uma ponte entre o cotidiano desses jovens conectados e as tecnologias que fazem parte de seu dia a dia nas práticas escolares. Com base nisso, a mídiaeducação é entendida, aqui, como um processo por meio do qual os cidadãos se tornam letrados midiaticamente. Ser letrado midiaticamente, conforme explicita o Media Literacy Week, implica que passem a estar aptos a "entender criticamente a natureza, as técnicas e os impactos das produções e mensagens da mídia"1, posicionando-se em relação ao mundo à sua volta.

Esse acesso às novas tecnologias, por seu turno, viabiliza, como afirma Freire (2009, p. 14) “[...] outras interfaces, práticas e linguagens, compelindo-nos a lidar com multiletramentos e a considerar requisitos originais tanto para o pertencimento de grupos específicos como para a definição do que poderia ser considerado inclusão ou exclusão".

\footnotetext{
${ }^{1}$ Traduzido do original no site Media Literacy Week: critically understand the nature, techniques and impacts of media messages and productions. Disponível em: https://medialiteracyweek.us/resources/media-literacy-basics/. Acesso em 11 de agosto de 2021.
} 
O trabalho com os multiletramentos, por essa razão, e com base na afirmação de Freire (2009) acima, passa a fazer parte do trabalho do professor ao interagir com jovens conectados e que usam as tecnologias móveis em seu cotidiano e as adicionam às práticas escolares. Logo, torna-se necessária a adoção de mecanismos que possam incorporar, a depender do contexto e do currículo, essas tecnologias aos currículos escolares.

Como resultado inerente, tem-se o professor trabalhando de modo multidisciplinar, uma vez que passa a utilizar as tecnologias em suas práticas de sala de aula, inserindo, desse modo, a chamada tecnologia educacional na escola. Coronado, Sainz e Navazo (2009) consideram que essa inserção permite propulsionar uma evolução na aprendizagem, passando de uma aprendizagem passiva a uma aprendizagem mais ativa. Os autores afirmam ainda que a tecnologia educacional permite que práticas outrora reservadas às elites se generalizem, tendo um impacto direto nas práticas sociais, já que, com isso, tem-se uma melhora na qualidade e um suposto barateamento dos custos de equipamentos.

Como se vê, as tecnologias móveis causaram um impacto significativo nas práticas sociais e temos, em suma, uma mudança nos modos como nos comunicamos e administramos nossas rotinas digitalmente. Essas rotinas, evidentemente, passaram a fazer parte das práticas escolares, por essa razão, aspectos relacionados ao ensino em ambientes digitais, uso de mídias na educação e outras práticas educativas envolvendo a tecnologia foram inseridas nos currículos e a mídiaeducação, foco deste trabalho, torna-se um elemento relevante a ser considerado no currículo escolar.

Em seu trabalho seminal sobre mídia-educação, Belloni (2009), ainda na primeira década do século XXI, discutia razões para a inserção das mídias na escola e apontava como aspecto mais importante o fato de que:

[...] a escola deve integrar as tecnologias de informação e comunicação porque elas já estão presentes e influentes em todas as esferas da vida social, cabendo à escola, especialmente à escola pública, atuar no sentido de compensar as terríveis desigualdades sociais e regionais que o acesso desigual a estas máquinas está gerando (BELLONI, 2009, p. 10).

Mais de uma década depois da publicação do trabalho de Belloni, presenciamos as tecnologias móveis como um elemento bastante presente observado 
em nossa prática pedagógica, já que é comum o fato de muitos alunos possuírem um aparelho de tecnologia móvel que lhe dá acesso a redes sociais e aplicativos.

Pelo fato de o primeiro autor atuar em uma escola pública da rede municipal na cidade de São Paulo onde foi implementado um currículo em que a mídia-educação é uma área do conhecimento, utilizamos aspectos dessa experiência para discutir as possíveis interfaces entre mídia-educação, as tecnologias e os multiletramentos.

Para atingir esse objetivo, discutimos, primeiramente, a relação entre mídiaeducação, as Tecnologias Digitais da Informação e Comunicação (TDIC) e os multiletramentos. Em seguida, apresentamos uma experiência com vídeos, realizada no âmbito da área de Mídia-educação, inserida no Projeto Político-Pedagógico (PPP) da escola em questão para, em um momento posterior, discutirmos a relevância da Pedagogia dos Multiletramentos para as futuras versões da área de conhecimento e para futuras adaptações no PPP. São apresentadas, após uma visão crítica sobre a presença dos multiletramentos em práticas de mídia-educação, nossas considerações finais sobre a experiência.

\section{Mídia-educação, currículo, TDICs e multiletramentos}

As mídias são parte integrante da cultura contemporânea e, como sinalizam Bévort e Belloni (2009, p. 1083), "[...] nela desempenham papéis cada vez mais importantes, sua apropriação crítica e criativa, sendo, pois, imprescindível para o exercício da cidadania".

Derivamos, dessa realidade apontada por Bévort e Belloni (2009), o fato de que as TDICs devem ser integradas às práticas escolares. Seu papel é fundamental, pois, como informam essas mesmas autoras, "[...] estas técnicas já estão presentes na vida de todas as crianças e adolescentes e funcionam - de modo desigual, real ou virtual - como agências de socialização, concorrendo com a escola e a família" (BÉVORT; BELLONI, 2009, p. 1084).

Da interface entre a mídia-educação e as TDIC, não podemos deixar de considerar a noção de currículo que deve embasar o trabalho prático e pressupõe, portanto, considerar a reflexão sobre os participantes envolvidos e o contexto em que a escola e seus participantes estão inseridos. Isso equivale a dizer que o currículo não pode ser pensado como algo pronto, que é passado ao docente como algo prescritivo 
a ser realizado, sem perspectivas de transformações, como já advertia Sacristán (2000).

Para que a relação entre a escola e a sociedade seja estabelecida, torna-se necessária a adoção de uma visão crítica de currículo, que seja um elemento mediador dessa relação escola/sociedade, ou seja, uma construção histórica e social, no dizer de Kemmis (1988).

Levando em consideração as comunidades de prática em que as atividades de mídia-educação são desenvolvidas, um elemento crucial a ser considerado junto aos alunos é a constante inserção de perguntas que os levem a questionar as práticas e a realidade que os cerca.

Ao realizar suas produções, portanto, os alunos devem ser motivados a questionar aspectos tais como: quem é o público da produção sendo realizada e por quê? A partir da perspectiva de quem a história está sendo contada? Como os elementos e códigos únicos de um gênero específico afetam o que vemos, ouvimos e lemos? Como diferentes públicos interpretam a mesma produção de mídia?, como sugerido pelo site do evento de mídia-educação Media Literacy Week (https://www.medialiteracyweek.ca/about/what-is-media-education/).

Essas perguntas permitem que, tanto as práticas desenvolvidas com os alunos quanto o currículo, estejam abertos a análises e críticas e, se necessário, que ocorram reencaminhamentos.

Nas práticas escolares atuais, o "convívio diário e quase que constante com recursos tecnológicos, em especial, com tecnologias móveis, como celulares e tablets, leva-nos a repensar sobre formas e conteúdos de aprendizagem", como afirmam Marques-Schäfer e Rozenfeld (2018, p. 9), e a mídia-educação pode ser entendida como uma maneira de repensar os conteúdos para o contexto escolar de forma a conviver com as tecnologias com as quais os alunos já utilizam convivem e estão em diálogo com o currículo.

A mera presença das tecnologias móveis nas salas de aula, no entanto, não promove o ensino nem a aprendizagem. Estas devem ser pensadas a partir das possibilidades e propiciações (affordances) que podem promover nos contextos educacionais e, por essa razão, uma Pedagogia de Multiletramentos deve ser considerada.

Rojo (2012) sinaliza para o fato de que devemos levar em consideração dois tipos específicos de multiplicidade presentes nas sociedades urbanas atuais: "[...] a 
multiplicidade cultural das populações e a multiplicidade semiótica de constituição dos textos por meio dos quais ela se informa e se comunica" (ROJO, 2012, p. 13).

Ao considerarmos a multiplicidade cultural ressaltada por Rojo (2012), automaticamente emerge um dos pilares da mídia-educação, uma vez que esta deve "[...] reconhecer e construir com base nas dimensões positivas, criativas e prazerosas da cultura popular2". Isso equivale a dizer que um currículo que inclua mídia-educação deve trabalhar com base na comunidade em que está inserido e, para isso, é importante que os alunos sejam levados a questionar a forma como são influenciados e influenciam a cultura local, como são afetados pelas mídias e como podem afetálas. Esses aspectos estiveram presentes nas atividades realizadas com mídiaeducação, conforme expomos na seção 3 .

\section{Uma experiência com vídeos no currículo do ensino fundamental}

A experiência com vídeos a partir da inserção da área de mídia-educação no currículo do ensino fundamental, descrita neste texto, faz parte de uma proposta de atividades que foram desenvolvidas por professores da área de mídia-educação de um Projeto ${ }^{3}$ com alunos do nono ano em uma Escola Municipal de Ensino Fundamental, na cidade de São Paulo. A ideia principal foi a de que os alunos criassem vídeos a partir de temas que lhes interessassem para serem publicados na revista da escola, mediante autorização fornecida para a escola por seus responsáveis em um termo de consentimento assinado no início do ano letivo em reunião de pais.

Sinalizamos aqui que, mesmo não tendo sido levada em consideração, na época de elaboração do PPP e da implementação da área de mídia-educação, há uma perspectiva de se trabalhar com uma multiplicidade de mídias, embora, à época, tal elemento não fosse explícito.

Iniciado em 2017 e amplamente aprovado pela comunidade escolar, o Projeto tem como objetivo romper com a fragmentação do ensino-aprendizagem para que não seja baseado em disciplinas estanques, fragmentada em aulas de 45 minutos. Esse

\footnotetext{
2 Traduzido do site Media Education Week: acknowledges and builds on the positive, creative and pleasurable dimensions of popular culture, disponível em: https://medialiteracyweek.us/resources/media-literacy-basics/. Acesso em 10 de agosto de 2021.

${ }^{3}$ Utilizaremos a palavra Projeto, com inicial maiúscula, para fazer referência às ações desenvolvidas na escola e disponíveis em sua revista online.
} 
rompimento dialoga diretamente com o que preceitua McLuhan (2017) em relação às novas preocupações com a educação, que, segundo o autor "vai na esteira da mudança dos currículos organizados segundo disciplinas estanques rumo à interrelação dos conhecimentos" (MCLUHAN, 2007, p. 54). Com base nessa inter-relação, o PPP da escola passou a ser organizado por áreas do conhecimento, quais sejam: Exatas, Humanas, Linguagens, Integradora e Mídia-educação.

A partir dessa nova organização, os tempos e os espaços da escola foram reconfigurados na tentativa de construir uma aprendizagem baseada em projetos de trabalho, pautados na pedagogia ativa (HERNÁNDEZ, 1998; FREIRE, 2015), para garantir a qualidade social da educação. O Projeto está organizado em torno de cinco princípios: autonomia, autoria, corresponsabilidade, democracia e investigação, de acordo com o PPP da escola.

Além da inclusão de mídia-educação no PPP da escola, a nova configuração constante do Projeto em desenvolvimento dispõe de um dia da semana para que os professores da mesma área do conhecimento se reúnam na escola para planejar suas atividades em conjunto. Com os alunos do $6^{\circ}$ ao $9^{\circ}$ ano no Ensino Fundamental II, os professores de cada área do conhecimento ficam responsáveis por uma das turmas durante 25 dias, fato que tem contribuído para fortalecer o vínculo entre professores e alunos. Com essa prática, um mesmo professor atua por seis aulas durante quatro dias da semana no decorrer dos 25 dias com a mesma turma. Desse modo, podemse criar vínculos afetivos com os alunos, conhecer suas reais dificuldades de aprendizagem, compartilhar com seus pares no planejamento semanal para buscarem possíveis soluções às dificuldades apresentadas pelo aluno.

\section{Mídia-educação no contexto do Projeto}

Segundo Cani e Coscarelli (2016), a escola enfrenta, entre alguns desafios, o de saber lidar com as diversas linguagens potencializadas pelas tecnologias digitais. O fato de se equipar a escola com os mais modernos equipamentos tecnológicos, por si, não garante aprendizagem, é necessário saber como utilizá-los. Como forma de solucionar esse problema de saber utilizar as tecnologias, o trabalho de mídiaeducação no contexto do Projeto tem como objetivo central trabalhar os elementos midiáticos para poder desenvolver nos alunos capacidade para: ler, escrever e participar como sujeito ativo dos meios de comunicação, tendo em vista as suas 
implicações, a partir de três frentes: "com as mídias, sobre as mídias e através das mídias" (PEREIRA, 2008, p. 58). Essas frentes devem atuar de maneiras interconectadas na promoção de sentido à aprendizagem dos alunos.

No trabalho pedagógico "com as mídias", o computador é usado como ferramenta para pesquisas na internet, para digitar textos e para preparar apresentações; o celular é usado para gravar e editar vídeos, tirar fotos, dentre outras possibilidades. Nesse caso, as mídias são os meios para a realização do trabalho pedagógico. Ao se trabalhar "sobre as mídias", há a possibilidade de promover debates a respeito de conteúdos e programas de TV, filmes, jornais, sites, uso crítico/reflexivo dos conteúdos disponíveis na internet, redes sociais, as fake news, uso de games para a promoção de aprendizagem, visitas a páginas de empresas produtoras de mídias etc. O objetivo é compreender o papel das mídias no processo de ensino-aprendizagem. Quando o trabalho ocorre "através das mídias", são desenvolvidas atividades para produzir blogs, documentários, vídeos, reportagens, entrevistas, telejornais, ou seja, tornar-se consumidor e produtor de conteúdo, a partir das mídias disponíveis. O objetivo, nesse caso, é que a mídia seja tanto o meio como a finalidade do trabalho pedagógico (PEREIRA, 2008, p. 58).

Nesse sentido, é possível afirmar que o trabalho com mídia-educação no contexto do Projeto pôde possibilitar a integração das TDIC presentes em distintas esferas da vida social das quais os alunos nele envolvidos fazem parte. Essa proposta de integração das TDIC vai ao encontro do que preceitua Belloni (2009) de usar a mídia-educação como forma de reduzir o acesso desigual e que todos os envolvidos possam participar tendo as mesmas oportunidades de acessibilidade.

\section{Proposta metodológica de trabalho com vídeos}

Como forma de criar oportunidades e promover as experiências de mídiaeducação no âmbito do Projeto, foi desenvolvida uma atividade de criação de vídeos para fazer uma reportagem em formato de um telejornal, os professores sugeriram que os alunos se organizassem em cinco grupos. Os grupos realizaram um sorteio para que cada um ficasse responsável por assistir a um telejornal de uma das TVs abertas (Globo, SBT, Record, Bandeirante e TV Cultura). Após o sorteio, cada grupo ficou responsável por fazer um debate em sala de aula sobre o conteúdo abordado no 
telejornal. Essa prática também teve como objetivo observar como são organizados estruturalmente esses telejornais.

Após a discussão realizada em sala de aula a respeito do que observaram no telejornal, os professores negociaram com os grupos a seguinte atividade: cada grupo poderia escolher algum problema que ocorresse no entorno da escola ou, em geral, um tema que provocasse impacto em suas vidas e criassem um vídeo no formato de um telejornal, como forma de uma possível intervenção sobre o problema levantado pelo grupo. Das discussões surgiram temas tais como Profissões, Aborto, Padrões de beleza, Poluição das águas, Atendimento na UBS do bairro, Vícios em games, dentre outros.

Para este artigo, por questões de espaço, selecionamos dois vídeos para discutirmos o papel dos multiletramentos no diálogo com a mídia-educação: Atendimento na UBS do bairro, produzido por alunas do nono ano C, e Poluição das águas, produzido por alunas do nono ano $\mathrm{A}$, para descrevermos como foi a experiência na realização da atividade na produção dos vídeos criados por elas.

No vídeo Atendimento na $U B S^{4}$, as alunas abordaram questões referentes ao atendimento no posto de saúde direcionado, principalmente, aos moradores residentes próximos à escola.

O vídeo retomou aspectos de um telejornal, mais especificamente, do Jornal Nacional da Rede Globo de televisão. A vinheta de abertura, o cenário com as iniciais do nome do jornal que criaram, e duas alunas no papel de âncoras apresentaram características análogas ao Jornal Nacional. Outros aspectos que estabeleceram relação com o gênero telejornal foram a "garota do tempo", com a apresentação da previsão do tempo, e a forma sucinta e objetiva de apresentar os noticiários e entrevistas devido às restrições de tempo.

A narrativa do vídeo girou em torno de três minutos, elaborado por um grupo de quatro alunas, duas fizeram o papel de âncoras e duas apareceram como repórteres em frente à UBS onde filmaram para entrevistar pessoas para saber como são atendidas naquela UBS. Uma das âncoras, antes de passar a palavra para as repórteres, enfatizou o fato de que tentaram contato com o responsável pela UBS, mas não obtiveram resposta.

\footnotetext{
${ }^{4}$ Por questões de preservação de identidade, omitimos o nome do bairro onde se localiza a escola, embora os vídeos estejam disponíveis na revista digital da escola: www.revistaduarte.com.br. Acesso em: 11 de agosto de 2021.
} 
Para o desenvolvimento dessa atividade, o grupo criou um roteiro com perguntas e explicitou o lugar onde deveriam ocorrer as entrevistas, o tempo e a função que cada componente do grupo deveria assumir. O material utilizado para a gravação do vídeo foi o próprio celular das integrantes do grupo, a ferramenta que utilizaram para fazer a edição do vídeo foi o VedeoShow ${ }^{5}$, aplicativo gratuito e disponível na Google Play, é também classificado como o aplicativo mais usado na criação e edição de vídeos gratuitos em muitos países.

Ao desenvolver essa atividade, as alunas puderam criar experiências de autoria e autonomia, que podem contribuir para o desenvolvimento de habilidades com o uso das TDIC, tornando-as mais conscientes, críticas e ativas no processo de construção do ensino-aprendizagem. Os multiletramentos são caracterizados na atividade a partir da "multiplicidade semiótica" (ROJO, 2012, p. 13), na constituição dos textos que elas constroem para produzir informação.

O vídeo $A$ poluição das águas ${ }^{6}$ tratou de um tema de caráter universal. Para discuti-lo com um viés pedagógico, relacionado ao contexto em que estão inseridas, as alunas ultrapassaram os muros da escola e foram até o córrego que passa próximo à escola onde estudavam. Para abordarem a poluição das águas nesse córrego, que há muito tempo tem sido objeto de descaso do poder público, fato que tem causado sofrimento aos moradores, devido ao mau cheiro do esgoto que corre a céu aberto, elas entrevistaram antigos moradores do bairro, que relataram com tristeza a situação atual do córrego que deságua em um rio maior.

O vídeo foi criado por cinco alunas, duas apareceram como apresentadora e comentarista, duas como repórteres e entrevistadoras e uma ficou nos bastidores, responsável pela parte técnica, para cuidar da gravação e edição. Ao contrário do anterior, este apresentou características que podem ser situadas mais ao gênero documentário do que da proposta inicial dos professores, que era a construção de um vídeo no formato de um telejornal. O vídeo durou cerca de oito minutos, iniciou com comentários das apresentadoras sobre possíveis causas de poluição das águas, na sequência há uma entrevista com uma aluna da escola e com uma moradora antiga do bairro e, por fim, as alunas/repórteres foram até a beira do córrego e mostraram

\footnotetext{
${ }^{5}$ Disponível em:

<https://play.google.com/store/apps/details?id=com.xvideostudio.videoeditor\&hl=pt_BR>. Acesso em: 12 de agosto de 2021.

${ }^{6}$ Disponível na revista digital da escola: www.revistaduarte.com.br. Acesso em: 12 de agosto de 2021.
} 
imagens para comentar sobre o risco de possíveis doenças a que os moradores estão sujeitos, devido ao excesso de sujeira na água do córrego.

O grupo finalizou o vídeo com uma apresentação de imagens que deslizaram em silêncio mostrando o real estado de destruição do córrego. Na sequência, ao som de uma trilha sonora, deslizou sobre a tela o letreiro, identificando os componentes do grupo, o nome da professora responsável, o tema do trabalho e papéis de cada integrante do grupo.

Para organizar a atividade, o grupo criou um roteiro com perguntas aos entrevistados, organização do cenário, tempo e lugares. O material usado para fazer as gravações e entrevistas foi o celular das próprias integrantes do grupo, como ferramenta para editar o vídeo usaram o aplicativo KineMaster ${ }^{7}$, disponível na Google Play. É um editor repleto de recursos para Android, apresenta ferramentas de fácil utilização como, por exemplo, camadas de vídeo, modos de mesclagem, controle de velocidade e efeitos especiais.

É possível afirmar que a atividade de produção de vídeos proposta pelos professores de mídia-educação e realizada pelas alunas do nono ano pode ser caracterizada como uma exitosa experiência do trabalho pedagógico, visto que nela foi potencializada a promoção dos multiletramentos (ROJO, 2012), a partir do uso de tecnologias disponíveis e que os alunos dominam.

Ao discutir o trabalho de Trindade (1992), Belloni (2009) aponta que a sobrevivência da sociedade ao mercado de trabalho do século XXI requer que o indivíduo desenvolva uma série de capacidades novas como, por exemplo, a autogestão (capacidade de organizar seu próprio trabalho), a resolução de problemas, a adaptabilidade e a flexibilidade diante das novas tarefas, a capacidade de "assumir responsabilidades e aprender por si próprio, desenvolver trabalho em grupo e pouco hierarquizado" (BELLONI, 2009, p. 23). O trabalho com vídeos desenvolvido pelas alunas, desse modo, pôde contribuir para conectá-las frente às novas demandas sociais do século XXI, donde podemos inferir que os aspectos de mídia-educação trabalhados durante as aulas foram apropriados pelos alunos no uso das TDIC ao executarem suas atividades no âmbito da área de mídia-educação.

\footnotetext{
${ }^{7}$ Disponível em: https://play.google.com/store/apps/details?id=com.nexstreaming.app.kinemasterfree\&hl=pt_BR. Acesso em 12 de agosto de 2021.
} 
Essas questões, no entanto, não devem ser consideradas apenas pelas perspectivas das mídias em si. Deve-se levar em consideração uma perspectiva mais ampla que agregue aspectos da cultura da convergência (JENKINS, 2009) em que esses sujeitos estão inseridos. Feitas tais considerações, criam-se possibilidades para que suas novas práticas textuais incorporem características de leitores imersivos (SANTAELLA, 2004) e da multiplicidade de possibilidades de remix em suas práticas. Dessa realidade, emerge a necessidade de incorporação de uma proposta de multiletramentos às práticas de mídia-educação.

A partir das propiciações possibilitadas pelas distintas tecnologias presentes nas salas de aula, pode-se efetivar o diálogo entre a mídia-educação e a Pedagogia dos Multiletramentos. Podemos ter, dessa forma, práticas escolares mais significativas e realistas, de acordo com o contexto. As propiciações, assim, podem ser pensadas como um elo entre ambas, como propõe a Figura 1:

Figura 1: As propiciações como elo entre mídia-educação e Pedagogia dos Multiletramentos

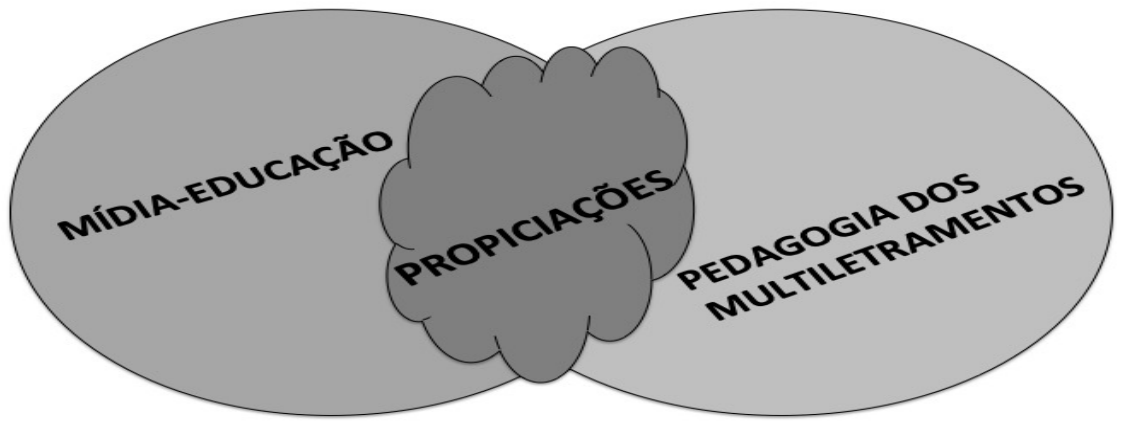

Fonte: Elaborada pelos autores

A Figura 1 tenta apreender a relação entre os elementos da mídia-educação, apontados por Pereira (2008), isto é, com as mídias, sobre as mídias e através delas e, com base nas propiciações que tais mídias e o contexto podem permitir, é possível considerar os multiletramentos e sua pedagogia incorporada às práticas escolares do contexto.

Os aspectos apontados por Belloni (2009) são extremamente relevantes e guiaram o projeto de implementação da área de mídia-educação na experiência aqui descrita. A integração de tecnologias de modo criativo e inteligente pôde contribuir para desenvolver a autonomia e competência dos alunos, "enquanto 'usuários' e criadores das TIC e não como meros 'receptores"', como sugere Belloni (2009, p. 8). $\mathrm{E}$, como se pode inferir pelas experiências descritas, as alunas utilizaram as TDIC 
para criar conteúdo digital na produção dos vídeos de forma autônoma, através de leitura crítica e escrita criativa com o uso de ferramentas digitais para abordar questões relacionadas a aspectos de sua vida e também conectadas ao currículo.

A partir do contato com novas teorias sobre o perfil cognitivo do leitor, de texto, da cultura de convergência e das novas práticas digitais, pretendemos ampliar o diálogo para as próximas práticas de mídia-educação que incorporarão uma Pedagogia de Multiletramentos em razão da multiplicidade cultural e de linguagens presentes na escola.

\section{Caminhos e possibilidades: um olhar crítico sobre mídia-educação}

Segundo Tufte e Christensen (2009), as crianças de hoje têm sido consideradas usuárias competentes e inovadoras no que diz respeito ao uso das novas mídias. Mesmo sendo usuárias competentes, ainda falta a elas uma compreensão cultural profunda das mídias e ferramentas para interpretar o cenário internacional das mídias comerciais, e da cultura midiática cotidiana. É importante, portanto, que essas habilidades sejam desenvolvidas pelos professores e é aí que se evidencia a necessidade da mídia-educação (TUFTE; CHRISTENSEN, 2009, p. 112).

Inserir o trabalho de mídia-educação hoje no currículo escolar é possibilitar ao aluno poder se conectar com o seu tempo, para explorar as diversas linguagens potencializadas pelo uso das diferentes mídias disponíveis na escola, no sentido de compreender as implicações educacionais, culturais, políticas e sociais em torno delas, a partir de um viés crítico e reflexivo. Essa perspectiva é condizente com o que indicava Belloni (2009), pois, segundo a autora, "a mídia-educação é hoje tão necessária ao exercício da cidadania quanto era a alfabetização no século XIX" (BELLONI, 2009, p. xiv).

Embora tenha um papel importante no contexto educativo, não parece haver de forma suficiente, no currículo do sistema educacional brasileiro, um componente específico para o estudo das mídias, no entanto, como sinalizado em Siqueira (2017), atualmente, tem aumentado o número de professores e pesquisadores interessados por esse tema. Além disso, já há indicação do trabalho com as mídias na Base Nacional Comum Curricular.

Inserir a mídia-educação no currículo escolar pode ser um caminho para viabilizar a possibilidade de se promoverem os multiletramentos na escola, 
principalmente, na potencialização de trabalhos voltados à leitura e escrita a partir das TDIC. A experiência realizada pelas alunas com a produção dos vídeos mostra evidências que comprovam nossa constatação. Na prática, isso ficou evidenciado no uso da técnica na utilização das mídias para organizar todo o trabalho desenvolvido como, por exemplo, no uso das TDIC para filmar e fazer edição dos vídeos para tratar de temas de seu entorno. Além disso, esse aspecto também pode ser visto na configuração, escolha e produção dos conteúdos. Uma dessas evidências é o fato de as alunas escolherem o tema para a criação do vídeo, pois, além de optarem por algo que estava relacionado ao seu cotidiano, promovendo, assim, o exercício da cidadania, tiveram que organizar o roteiro, discutir em grupo o papel representado por cada uma no trabalho, e escolher as ferramentas digitais para a criação e edição.

Torna-se necessário, desse modo, desenvolver o letramento midiático. Conforme explicitado por Barbosa e Vian Jr. (2018), é necessário desenvolver uma abordagem crítica aos textos midiáticos e, por essa razão, em um currículo de mídiaeducação, devem-se abordar os multiletramentos, pois os alunos farão uso de tecnologias digitais para suas práticas, estarão interagindo com sua comunidade e devem ser desenvolvidas práticas em que o papel do letramento midiático e sua inserção em uma perspectiva mais ampla de uma Pedagogia de Multiletramentos seja abordada.

Acresça-se, ainda, o fato de estarmos lidando com alunos com um novo perfil cognitivo e o tratamento que dispensam às mídias e às tecnologias em suas vidas deve levar tal fato em consideração. Trata-se, como indicado por Santaella (2004) do "leitor imersivo", isto é, o leitor que, segundo a autora:

[...] começa a emergir nos novos espaços incorpóreos da virtualidade", substituindo o leitor contemplativo, da idade pré-industrial, e o leitor movente, filho da Revolução Industrial, que o precederam, que não leem mais em bibliotecas ou no jornal, mas nas telas e nos "espaços incorpóreos da virtualidade (SANTAELLA, 2004, p. 19).

Esse leitor imersivo atua em uma cultura de convergência (JENKINS, 2009) dos meios de comunicação. A convergência, como postula Jenkins (2009, p. 44), "[...] envolve uma transformação tanto na forma de produzir quanto na forma de consumir os meios de comunicação". Com base na citação de Jenkins (2009), podemos dizer que estamos tratando diretamente do leitor imersivo e, ao produzir suas atividades em 
mídia-educação, deve ter consciência de seu papel nessa cultura, de modo que não consumam e nem produzam mídia de forma ingênua.

Para que tais práticas ocorram, deve-se encaminhar uma Pedagogia dos Multiletramentos. Essas práticas de multiletramentos, conforme proposto pelo Grupo de Nova Londres (1996) e posteriormente abordada no Brasil por Rojo (2012), devem incluir um usuário funcional, criador de sentidos, analista crítico e transformador.

Conforme sinalizado pela autora (ROJO, 2012), essas possibilidades serão possíveis e deverão ocorrer "a partir de um enquadramento dos letramentos críticos que buscam interpretar os contextos sociais e culturais de circulação e produção desses designs e enunciados" [itálicos no original] (ROJO, 2012, p. 30).

Em nosso caso, temos que a inserção da mídia-educação pelo simples fato de inserir mídias na escola não basta. É necessário levar em consideração a multiplicidade de culturas em que os jovens que irão produzir essas mídias estejam inseridos, uma vez que os leitores imersivos (SANTAELLA, 2004) nos contextos escolares atuais podem ser caracterizados, como preceitua Jenkins, a partir do termo empregado por Certeau, de "invasores de texto" (JENKINS, 2015), já que os fãs roubam o texto para seu próprio uso e, por essa razão, as práticas de mídia-educação devem, daqui por diante, considerar essas novas realidades.

Uma das considerações mais relevantes nessa interface entre mídia-educação e Pedagogia dos Multiletramentos são as propiciações (affordances) que cada tecnologia e cada mídia pode proporcionar para o processo de ensino-aprendizagem em relação ao contexto em que as práticas ocorrem. Como bem sinalizado por Kress (2014, p. 61), as ações sociais, em conjunto com as propiciações que os elementos materiais da cultura possibilitam é que produzem os recursos semióticos naquela dada cultura, como apontamos a partir dos problemas sociais do contexto em que a escola está inserida e detectados pelos alunos para suas produções em vídeo.

\section{Considerações finais}

Nosso principal objetivo neste texto foi o de tecer considerações, a partir de uma experiência prática, sobre como uma Pedagogia de Multiletramentos deve ser considerada para ser incorporada à mídia-educação e o uso de novas tecnologias digitais. 
Apresentamos, especificamente, duas atividades desenvolvidas por alunas em uma escola pública na cidade de São Paulo, e como podem fazer uso das TDIC presentes em seu cotidiano e utilizadas como forma de interação em suas comunidades. Foi abordado, também, como tais ferramentas podem ser incorporadas e exploradas pedagogicamente no cotidiano escolar, para a criação de sentido em situações de ensino-aprendizagem no âmbito do currículo escolar.

Em experiências futuras, os aspectos de mídia-educação e das tecnologias abordados no presente artigo, tais como, produzir vídeos que retratem problemas locais e as demais tarefas envolvidas para que possam participar como cidadãos ativos, críticos e reflexivos em ambientes digitais, com o uso das TDIC, assim como as distintas possibilidades de abordagem dos multiletramentos em atividades pedagógicas poderão ser incorporadas para ampliar a discussão de novas práticas da cultura digital no contexto escolar.

\section{Referências}

BARBOSA, M.R.S.A.; VIAN JR., O. Letramento midiático: inserção do diálogo entre texto visual e verbal no ensino fundamental. Calidoscópio. [S. I.], v. 16, n. 3, p. 380391 , 2018. Disponível

em: http://revistas.unisinos.br/index.php/calidoscopio/article/view/cld.2018.163.03. Acesso em: 13 de agosto de 2021.

BELLONI, M.L. O que é mídia-educação. 3. ed. Campinas, SP: Autores Associados, 2009.

BÉVORT, D.; BELLONI, M.L. 2009. Mídia-educação: conceitos, história e perspectivas. Educação \& Sociedade, Campinas, vol. 30, n. 109, p. 1081-1102, 2009. Disponível em <http://www.cedes.unicamp.br>. Acesso em 10 de agosto de 2121.

CANI, J.B.; COSCARELLI, C.V. Textos multimodais como objetos de ensino: reflexões em propostas didáticas. In: KERSCH, D.F.; COSCARELLI, C.V.; CANI, J.B. (Orgs). Multiletramentos e multimodalidade: ações pedagógicas aplicadas à linguagem. Campinas, SP: Pontes Editores, 2016.

CORONADO, M.L.; SAINZ, B.; NAVAZO, M.A. Nuevas tecnologías y su uso en educación. In: SOTO, U.; MAYRINK, M.F.; GREGOLIN, I.V. Linguagem, educação e virtualidade. São Paulo: Cultura Acadêmica, 2009, p. 69-91.

FREIRE, M. M. Formação tecnológica de professores: problematizando, refletindo, buscando... In: SOTO, U.; MAYRINK, M.F.; GREGOLIN, I.V. Linguagem, educação e virtualidade. São Paulo: Cultura Acadêmica, 2009, p. 13-28. 
FREIRE, P. Pedagogia do oprimido. 59. ed. ver. e atual. Rio de Janeiro: Terra e Paz, 2015.

HERNÁNDEZ, F. Transgressão e mudança na educação: os projetos de trabalho. Tradução. Jussara Haubert Rodrigues. Porto Alegre: Artmed, 1998.

JENKINS, H. Cultura da convergência. São Paulo: Aleph, 2009.

JENKINS, H. Invasores do texto - Fãs e cultura participativa. Nova Iguaçu/RJ: Marsupial Editora, 2015.

JUVENTUDE CONECTADA 2. Fundação Telefônica Vivo. 1a. ed. São Paulo: Fundação Telefônica Vivo, 2016.

KEMMIS, S. El currículo: más allá de la teoria de la reproducción. Madrid: Morata, 1988.

KRESS, G. What is mode? In: JEWITT, C. The Routledge handbook of multimodal analysis. London \& New York: Routledge, 2014, p. 60-75.

MCLUHAN, M. Os meios de comunicação como extensões do homem. Tradução. Décio Pignatari. São Paulo: Cultrix, 2007.

MARQUES-SCHÄFER, G.; ROZENFELD, C.C.F. (Orgs.). Ensino de línguas e tecnologias móveis: políticas públicas, conceitos, pesquisas e práticas em foco. São Paulo: Edições Hipótese, 2018.

MEDIA EDUCATION WEEK. Disponível em:

https://www.medialiteracyweek.ca/about/what-is-media-education/. Acesso em: 10 de agosto de 2021.

PEREIRA, S. da C. Mídia-educação no contexto escolar mapeamento crítico dos trabalhos realizados nas escolas de ensino fundamental em Florianópolis. Dissertação de mestrado em Educação. Universidade Federal de Santa Catarina, 2008.

ROJO, R. Pedagogia dos multiletramentos: diversidade cultural e de linguagens na escola. In: ROJO, R.; MOURA, E. Multiletramentos na escola. São Paulo: Parábola, 2012.

SACRISTÁN, J.G. O currículo: uma reflexão sobre a prática. Porto Alegre: Artmed, 2000.

SANTAELLA, L. Navegar no ciberespaço - O perfil cognitivo do leitor imersivo. São Paulo: Paulus, 2004.

SOTO, U.; MAYRINK, M.F.; GREGOLIN, I.V. Linguagem, educação e virtualidade. São Paulo: Cultura Acadêmica, 2009. 
SIQUEIRA, A.B de. Materiais didáticos de mídia-educação. Educ. Soc., Campinas, v. 38, n. 138, p.209-227, jan-mar., 2017.

TUFTE, B.; CHRISTENSEN, O. Mídia-Educação: entre a teoria e a prática. Perspectiva, Florianópolis, v. 27, n. 1, 97-118, jan./jun. 2009.

Recebido em 31/07/2020

Aceito em 10/08/2021

Publicado em 24/08/2021 